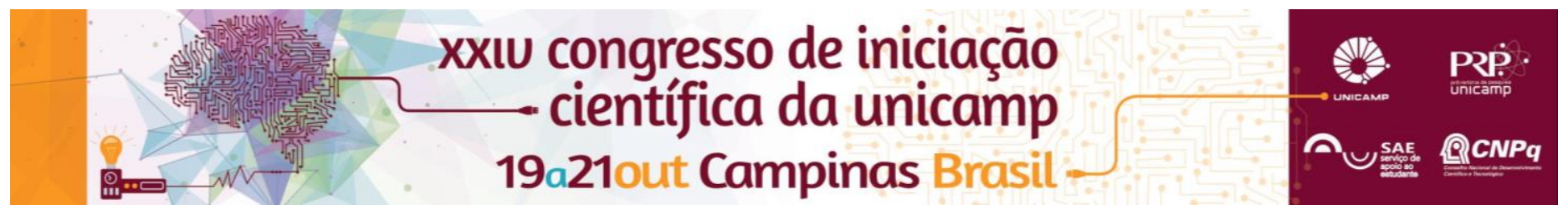

\title{
Avaliação reológica e termomecânica de farinhas de trigo comerciais: uma nova abordagem
}

\author{
Gabriela M. Oliveira*, Marcio Schmiele, Fernanda Ortolan, Maria T.P.S. Clerici, Yoon K. Chang.
}

\section{Resumo}

A utilização do Mixolab na avaliação da qualidade termomecânica de farinha de trigo no Brasil ainda é emergente. No entanto, é possível avaliar o comportamento da massa submetido a estresse mecânico e térmico como um todo, e não individualmente como nas demais análises reológicas. Dessa forma, o objetivo deste trabalho foi investigar se há correlação nos parâmetros reológicos de farinhas de trigo comerciais obtidos no Mixolab e farinógrafo.

\section{Palavras-chave:}

Mixolab, farinógrafo, reologia.

\section{Introdução}

A composição química da farinha de trigo (FT), principalmente em relação as proteínas formadoras da rede de glúten, determina o comportamento reológico da massa formada, o qual é verificado por análises reológicas para definir a aplicação das FTs.A avaliação por Mixolab apresenta algumas vantagens, pois é capaz de avaliar vários parâmetros da massa (absorção de água, estabilidade, consistência, gelatinização do amido, atividade diastásica e retrogradação) através de trabalho mecânico e variação da temperatura, utilizando pouca amostra em um tempo muito mais curto ${ }^{1}$. O objetivo deste trabalho foi avaliar a classificação e a correlação entre o Mixolab e a farinografia de 10 amostras comerciais de FT.

\section{Resultados e Discussão}

A Tabela 1 apresenta os parâmetros para classificação da FTe a Figura 1 mostra uma curva padrãode Mixolab. A Tabela 2 exibe a classificação das FTs avaliadas.Os resultados mostram que somente a amostra $G$ não apresentou o mesmo comportamento.

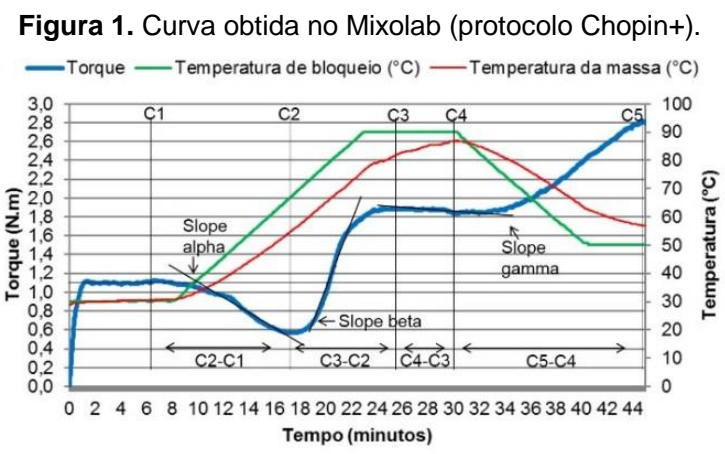

C1 - Consistência da massa $(1,1 \pm 0,05 \mathrm{~N} . \mathrm{m})$; C2 (enfraquecimento proteico); C3 (gelatinização do amido) C4 (estabilidade do gel no cozimento); C5 (retrogradação durante o esfriamento), C2-C1 (intensidade do enfraquecimento da rede de glúten), C3-C2 (grau de gelatinização do amido), C4-C3 (grau de estabilidade do amido ao cozimento), C5-C4 (grau de retrogradação do amido), Slope a (velocidade de enfraquecimento da rede de glúten), Slope $\beta$ (velocidade de gelatinização do amido) e Slope y (velocidade de ação da alfa-amilase) ${ }^{1}$.

Nas demais amostras, embora a classificação não seja estritamente a mesma, pode-se verificar que estão muito próximas, exibindo a mesma tendência. Quando comparadas as absorções de água verificou-se a mesma tendência para o farinógrafo e o Mixolab. Maior quantidade de água absorvida também aumenta a velocidade de gelatinização do amido $(\beta)$, pois os grânulos de amido podem romper-se e absorver água mais rapidamente. Além disso, uma maior estabilidade da FT resulta em menor enfraquecimento da rede de glúten, característica de farinhas fortes.

Tabela 1. Parâmetros de classificação da farinha de trigo por Mixolab.

\begin{tabular}{|l|c|c|c|}
\hline & Fraca & Forte & $\begin{array}{c}\text { Muito } \\
\text { forte }\end{array}$ \\
\hline ABS(\%) & 50,1 & 55,6 & 58,3 \\
\hline C2 $(\mathrm{nm})$ & 0,43 & 0,45 & 0,47 \\
\hline C3 $(\mathrm{nm})$ & 2,06 & 2,03 & 1,87 \\
\hline C3-C2 $(\mathrm{nm})$ & 1,63 & 1,58 & 1,4 \\
\hline C4 & 1,68 & 1,77 & 1,5 \\
\hline C5 & 3,34 & 2,57 & 2,41 \\
\hline Estabilidade & 4,9 & 7,3 & 9 \\
\hline
\end{tabular}

Tabela 2. Classificação das farinhas pelo manual do Mixolab e do Farinograph Handbook

\begin{tabular}{ccc}
\hline Farinha & Mixolab & Farinografia \\
\hline A & Forte & Média \\
B & Forte & Média \\
C & Fraca & Média \\
D & Muito forte & Forte \\
E & Muito forte & Forte \\
F & Forte & Forte \\
G & Muito forte & Fraca \\
H & Forte & Forte \\
I & Muito forte & Forte \\
J & Fraca & Fraca \\
\hline
\end{tabular}

Figura 2. Correlação de Pearson entre a farinografia e o Mixolab.

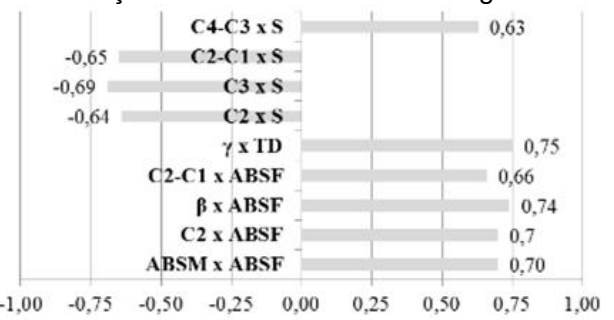

ABSM - absorção de água do Mixolab; ABSF - absorção de água no farinógrafo; TD - tempo de desenvolvimento; S - estabilidade.

\section{Conclusões}

O Mixolab demonstrou gerar resultados que se correlacionam parcialmente com a farinografia. Trata-se de uma técnica rápida e eficaz na caracterização reológica e termomecânica de FT, podendo prever o comportamento de proteínas, amido, enzimas e aditivos.

\section{Agradecimentos}

Aos moinhos Anaconda, Sul Mineiro, Corina e Paulista e ao Pastifício Selmi pela doação das farinhas. À Granotec do Brasil e à Bimbopor viabilizar o uso do Mixolab.

${ }^{1}$ Rosell, C.M., Santos, E., \& Collar, C. Physicalcharacterization of fiberenriched bread doughsby dual mixing and

temperatureconstraintusingtheMixolab®. EuropeanFoodResearch and Technology, 2010. 231, 535-544. 